\title{
Escolarização de jovens e adultos com deficiência intelectual: considerações sobre as pesquisas em dissertações e teses no período de 1988 a 2008
}

\author{
Jéssica de Brito* \\ Juliane Ap. de Paula Perez Campos**
}

\begin{abstract}
Resumo
O objetivo deste estudo foi investigar produções científicas sobre a temática da educação de jovens e adultos com deficiência intelectual, presentes em dissertações e teses no período de 1988 a 2008. Para isso, realizouse o levantamento no banco de teses da Capes, por meio de busca com descritores específicos que contemplassem a educação de jovens e adultos, educação especial, e deficiência intelectual e mental. Foram selecionadas dez produções distribuídas em seis Instituições de Ensino Superior (IES), a maioria oriundas de IES públicas, relativas ao Programa de Pós-Graduação em Educação, e defendidas na década de 2000. A maior parte dos estudos incidiu sobre a alfabetização e sinalizou a necessidade de aprimoramento das práticas pedagógicas, bem como a importância da interação dos jovens e adultos portadores de deficiência intelectual com seus professores. Verificouse ainda a existência de poucos estudos pertinentes a essa população em questão; apontando para um campo de conhecimento a ser devidamente desvendado.
\end{abstract}

Palavras-chave: Alunos com deficiência intelectual; Educação de jovens e adultos; Educação Especial.

\footnotetext{
* Acadêmica de Educação Especial pela Universidade Federal de São Carlos (UFSCar), São Carlos, São Paulo.

** Professora Doutora do Departamento de Psicologia. Curso de Licenciatura em Educação Especial. Universidade Federal de São Carlos (UFSCar), São Carlos, São Paulo.
}

Revista Educação Especial | v. 26 | n. 45, | p. 45-58 | jan./abr. 2013

Santa Maria

Disponível em: <http://www.ufsm.br/revistaeducacaoespecial> 


\title{
Schooling of young and adults people with intellectual disabilities: considerations on research dissertations and theses in the period 1988 to 2008
}

\begin{abstract}
The objective of this study was to investigate the scientific production on the theme of youth and adults with intellectual disabilities, found in dissertations and theses in the period 1988 to 2008. For this, we carried out the survey on the bank of the CAPES, by searching with keywords specific to contemplate the education of youth and adults, special education, and intellectual disability and mental. We selected ten productions distributed in six Higher Education Institutions (HEI), the majority coming from public higher education institutions, for the Graduate Program in Education, and defended in the 2000s. Most studies focused on literacy and signaled the need for improvement of teaching practices, as well as the importance of the interaction of young people and adults with intellectual disabilities with their teachers. It was also found that there are few studies relevant to this population in question, pointing to a field of knowledge to be properly understood.
\end{abstract}

Keywords: Students with intellectual disabilities; Youth and adult special education

\section{Introdução}

A inclusão de alunos com deficiência no ensino regular tem sido um dos principais pontos de discussão no âmbito educacional. Dentre os muitos desafios em que se coloca a educação inclusiva, particularmente a educação especial, está a escolarização de jovens e adultos com deficiência.

Meletti e Gonçalves (2010) realizaram uma pesquisa sobre os microdados do Censo Escolar em relação às matrículas de jovens e adultos com deficiência na EJA. Os dados gerais dessas matrículas no Brasil foram 38.720 obtidos em escolas comuns. Em contrapartida, o número de matrículas de alunos com deficiência intelectual nos anos iniciais da EJA alcançou 13.344 matrículas. Tais dados sinalizam amplamente a crescente presença desse novo alunado: a de jovens e adultos com deficiência. Mencione-se que ainda são escassas as pesquisas brasileiras sobre essa população e também estudos que contemplem efetivas ações educacionais ligadas à inclusão social e educacional. 
Com isso, o papel da escola, a formação e atuação do corpo docente, as questões pedagógicas relacionadas ao processo ensino-aprendizagem, dentre outros aspectos, tornaram-se imprescindíveis e passaram a ser (re) pensados por autoridades governamentais, pesquisadores e profissionais da educação de diferentes níveis e modalidades de ensino.

Diante da perspectiva do acesso a todos a uma escola de qualidade, insere-se a proposta inclusiva, na qual se entende efetivamente por inclusão:

[...] a garantia, a todos, do acesso contínuo ao espaço comum da vida em sociedade, sociedade essa que deve estar orientada por relações de acolhimento à diversidade humana, de aceitação das diferenças individuais, de esforço coletivo na equiparação de oportunidades de desenvolvimento, com qualidade, em todas as dimensões da vida. (BRASIL, 2001, p.39-40)

Concomitantemente ao movimento da integração, o objetivo da inclusão escolar é tornar reconhecida e valorizada a diversidade como condição humana favorecedora de aprendizagem. Desse modo, ao invés de "aproximar" o aluno com necessidades educacionais especiais dos chamados padrões de normalidade, a ênfase está na identificação de suas potencialidades, culminando com a construção de alternativas para garantir condições favoráveis à sua autonomia escolar e social (PRIETO, 2006).

Além disso, a educação inclusiva constitui um paradigma educacional fundamentado na concepção de direitos humanos, que conjuga igualdade e diferença como valores indissociáveis, e que avança em relação à ideia de equidade formal ao contextualizar as circunstâncias históricas da produção da exclusão dentro e fora da escola (BRASIL, 2008).

Diante desse fato, ao se pensar a inclusão deve-se refletir nesse novo "modelo" de escola que atenda a todos indistintamente, e também repensar a escola em razão das novas demandas da sociedade atual e das exigências e direitos desse novo alunado.

A partir da Constituição Federal de 1988 e das Leis de Diretrizes e Bases da Educação (9.394/96), a Educação de Jovens e Adultos (EJA) passa a ter uma atenção maior no cenário educacional brasileiro; sendo prescrita enquanto modalidade da educação básica, bem como do direito do jovem e do adulto ao ensino fundamental público. Contudo, malgrados tais conquistas, o que se vê é mais um percurso de descaso e omissão do governo brasileiro, já de muitas décadas. 
Como sinaliza Di Pierro (2008, p. 397):

O desrespeito aos direitos educativos dos jovens e
adultos resulta, dentre outras causas, da postergação
do tema nas políticas governamentais. No Brasil,
como em quase toda a América Latina, a educação
de jovens e adultos ocupou, no desenvolvimento do
sistema de ensino público, um papel subsidiário às
demais modalidades, cumprindo função compensatória
de reposição de escolaridade não realizada na idade
considerada apropriada, ou de aceleração de estudos de
pessoas com atraso escolar.

Em outro contexto, a área da Educação Especial também sinaliza avanços importantes ao longo das duas últimas décadas. Conforme a Política Nacional de Educação Especial na Perspectiva da Educação Inclusiva (BRASIL, 2008), as modalidades de educação de jovens e adultos e educação profissional apresentam-se como possibilidades de ampliação de oportunidades de escolarização, formação para a inserção no mundo do trabalho e efetiva participação social das pessoas com deficiência.

Tomemos como referência a escolarização de pessoas com deficiência intelectual

De acordo com a definição da Associação Americana de Retardo Mental, AARM (2002), a deficiência intelectual é caracterizada por limitações significativas no funcionamento intelectual e no comportamento adaptativo expressadas nas habilidades adaptativas conceituais, sociais e práticas; tendo sua origem antes dos 18 anos.

Conforme Smith (2008), muitas das pessoas com deficiência intelectual são capazes de trabalhar, de estabelecer relacionamentos com amigos e família, e realizar as atividades desejadas; enquanto outros necessitam de assistência e apoio constantes. No entanto, a deficiência intelectual, assim como as demais, desafia muitas escolas comuns em seu objetivo de ensinar e de levar o aluno a aprender o conteúdo curricular, construindo o conhecimento.

Infelizmente, pesquisas apontam outra realidade quanto à preparação de pessoas com deficiência para o trabalho. Mendes e colaboradores (2006), ao analisarem pesquisas sobre diferentes aspectos do processo de profissionalização da pessoa com deficiência, sinalizaram achados importantes que refletem o cenário de preparação e inserção profissional de pessoas com deficiência no Brasil. Os resultados indicaram a precariedade do serviço e do treinamento oferecido; as modalidades de 
oficinas oferecidas eram desvinculadas das necessidades do mercado de trabalho; na maioria das instituições, os alunos eram tratados como crianças, não opinavam a respeito de seu futuro; nenhuma instituição oferecia uma profissão para o indivíduo com deficiência intelectual, e as atividades eram de cunho artesanal.

Tomando-se por base esses estudos, é possível visualizar o cenário profissional voltado para essa parcela significativa de pessoas com deficiência que passaram anos e anos nas instituições especiais, assim como as dificuldades enfrentadas por estas instituições, quanto ao ensino de habilidades importantes relacionado a tarefas específicas e ao relacionamento social entre os colegas de trabalho.

Atualmente, tais desafios são deslocados para as escolas regulares. Uma das questões recentes na escolarização de alunos com deficiência intelectual está em fazer cumprir a "terminalidade específica" prevista em lei (LDBN 9.394/96), por meio da certificação de conclusão de escolaridade, focada nas competências desenvolvidas pelo educando, bem como o encaminhamento devido desses alunos para a educação de jovens e adultos à educação profissional.

Nessa perspectiva, pensar a respeito do alunado jovem e adulto com deficiência intelectual implica refletir acerca da interface entre educação especial e educação de jovens e adultos.

No entanto, é possível notar poucas investigações sobre tais contextos que visem estabelecer diálogos e questionamentos; sendo estes por sua vez excluídos dos "espaços escolares", não conseguindo responder às demandas desse alunado.

Rubin (2003) aponta que as preocupações e os estudos da educação especial e da educação de forma geral ainda se direcionam mais à aprendizagem de crianças, predominando significativamente nesta área do que na área de pesquisas que investigam a aprendizagem de jovens e adultos. Além disso, Nunes e colaboradores (1998; 1999), ao analisarem a produção discente (de 1981 a 1995) na área da educação especial de dois programas de pós-graduação do país, indicaram que o tema ensinoaprendizagem foi o que mais apareceu, com destaque para a alfabetização.

A história tem demonstrado que a Educação de Jovens e Adultos ainda esta longe de ser um espaço de inclusão de pessoas com deficiência, caracterizado que é pela ausência de uma articulação efetiva dessa modalidade de ensino com a da Educação Especial, pois, segundo Moraes (2007), a Educação de Jovens e Adultos ainda não tem-se caracterizada, em 
nosso país, como espaço de inclusão e acolhimento das diferenças; embora sempre se constituísse como um espaço ocupado pelas "minorias", pelos segmentos discriminados da sociedade brasileira.

Diante desse cenário, é recente a inclusão nas escolas regulares de pessoas com deficiência intelectual nos programas de educação de jovens e adultos. Para Haddad e Di Pierro (2000), o desafio da expansão do atendimento na educação de jovens e adultos já não reside apenas na população que jamais foi à escola, mas se estende àquela que frequentou os bancos escolares, mas neles não obteve aprendizagens suficientes para participar plenamente da vida econômica, política e cultural do país e seguir aprendendo ao longo da vida.

Portanto, (re) conhecer como a escola brasileira foi, é, e está sendo organizada para os jovens e adultos com deficiência intelectual, torna-se fundamental neste momento. Qual tem sido o foco de interesse nas pesquisas sobre educação de jovens e adultos e alunos com deficiência intelectual?

Com tais indagações, este estudo teve como objetivo investigar a produção científica nacional sobre a temática "escolarização de jovens e adultos com deficiência intelectual" publicada no período de 1988 a 2008.

\section{Percurso metodológico}

Esta pesquisa teve como foco o estudo exploratório-descritivo, tomando-se por base a técnica da pesquisa bibliográfica. Gil (2008); Lima e Mioto (2007) relatam que essa técnica tem sido utilizada com grande frequência em estudos exploratórios ou descritivos, casos em que o objeto de estudo proposto é pouco estudado, e implica um conjunto ordenado de procedimentos de busca de soluções, atento ao objeto de estudo.

Aamostragem considerada incluiu a pesquisa da temática "educação de jovens e adultos com deficiência intelectual" em dissertações e teses dos programas de pós-graduação em Psicologia, Educação e Educação Especial defendidas no período de 1988 a 2008, tendo como referência o Banco de Teses e Dissertações da Capes.

O levantamento das dissertações e teses no referido banco de dados foi realizado através da busca com descritores específicos que contemplassem a educação de jovens e adultos, educação especial, e deficiência intelectual ou mental. A partir dessa etapa - seguida de leitura exploratória e seletiva - realizou-se a catalogação das informações dos vinte resumos informados identificando: instituição; ano de defesa; programa de pós-graduação; tipo de documento; tema principal; tema secundário; objetivos; tipo de pesquisa; 
participantes; instrumentos/procedimentos para coleta dos dados; fonte de coleta dos dados; resultados e conclusão.

Os dados coletados e descritos passaram por análise quantitativa e qualitativa. A primeira análise prevê a quantificação (em diferentes níveis) das produções acadêmicas encontradas que estão relacionadas ao objeto do referido estudo, com os dados organizados em gráficos e tabelas. Já o segundo tipo de análise refere-se a uma reflexão crítica do conteúdo indicado nas descrições dos itens citados anteriormente, organizados em eixos temáticos.

\section{Resultados e discussão}

Dos vinte resumos analisados, foram localizadas dez produções referentes às dissertações e teses defendidas no período de 1988 a 2010 dos programas de pós-graduação em Educação, Educação Especial e Psicologia e suas respectivas Instituições de Ensino Superior (BINS, 2007; CARVALHO (2004), RUBIN (2003), SHIMAZAKI (2006), FREITAS (2008), IACONO (2004), SÓLERA (2008), TINÓS (2010), TRAVAGLINE (2004), XAVIER (2007)).

Conforme indicado na Tabela 1, pode-se observar que, das dez produções selecionadas, seis Instituições de Ensino Superior (IES) equivalem a $78 \%$ oriundas das IES públicas e $22 \%$ das privadas. A maioria das IES localiza-se nas regiões Sudeste e Sul, tendo como referência o Programa de Pós-Graduação em Educação. Dentre os dados apresentados, chama a atenção a localização de duas produções pertencentes ao Programa de PósGraduação em Educação Especial.

\begin{tabular}{|c|c|c|c|}
\hline IES & $\begin{array}{c}\text { Programa de Pós- } \\
\text { Graduação }\end{array}$ & Titulação & Ano de defesa \\
\hline USP & Educação & Doutorado & 2006 \\
& Psicologia & Mestrado & 2008 \\
\hline UFSCAR & Educação Especial & Mestrado & 2003 \\
& Mestrado & 2010 \\
\hline UNICAMP & Educação & Doutorado & 2004 \\
\hline UEM & Educação & Mestrado & 2004 \\
& Educação & Mestrado & 2008 \\
\hline UNIMEP & Mestrado & 2007 \\
& Educação & Mestrado & 2004 \\
\hline PUC-RS & & \multicolumn{2}{|c}{} \\
\hline
\end{tabular}

Tabela 1. Instituições de Ensino Superior (IES), Programas de Pós-Graduação, Titulação e Ano de Defesa das produções 
Embora o documento da Constituição Brasileira de 1988 seja marco no estudo e desenvolvimento de políticas de inclusão no cenário da educação brasileira, bem como na oferta do direito à educação fundamental da população jovem e adulta, verificou-se que as produções localizadas datavam da década de 2000, e apenas três referiam-se ao nível de doutorado. Com isso, pode-se entender que são recentes as pesquisas voltadas à educação de jovens e adultos com deficiência intelectual; o que reflete a urgência na investigação dessas pessoas em diferentes contextos educacionais.

Em relação aos objetivos propostos pelos resumos das teses e dissertações selecionadas (Tabela 2), observa-se que grande parte desses estudos teve como meta conhecer, analisar e descrever determinado objeto de estudo. Além disso, a maioria obteve como referencial teórico a abordagem histórico-cultural.

\begin{tabular}{|l|c|}
\hline \multicolumn{1}{|c|}{ Foco de estudo } & $N^{\circ}$ de trabalhos \\
\hline $\begin{array}{l}\text { Alfabetização de jovens e adultos com deficiência intelectual e ensino de } \\
\text { português e matemática. }\end{array}$ & 3 \\
\hline Trajetórias escolares dos jovens e adultos com deficiência intelectual. & 2 \\
\hline $\begin{array}{l}\text { Análise e investigação das concepções dos funcionários de uma instituição } \\
\text { especial sobre a diferença/deficiência. }\end{array}$ & 1 \\
\hline $\begin{array}{l}\text { Aquisição dos processos de leitura e escrita pelos jovens e adultos com } \\
\text { deficiência intelectual e o conhecimento sobre o termo "Terminalidade } \\
\text { Específica" }\end{array}$ & 2 \\
\hline $\begin{array}{l}\text { Análise pelos professores dos alunos com deficiência intelectual em vários } \\
\text { espaços como sala de aula, pátio, etc. }\end{array}$ & 2 \\
\hline
\end{tabular}

Tabela 2: Foco de interesse/ objetivos localizados nas dissertações e teses selecionadas.

Algumas dessas pesquisas tiveram como interesse o estudo das práticas de alfabetização e letramento, aquisição da leitura, da escrita e da matemática pelos alunos, enquanto outras focalizaram a permanência desse alunado na escola regular; tendo como questionamento o significado da terminalidade específica.

Sobre as práticas de alfabetização e letramento, Freitas (2008), Rubin (2003) e Shimazaki (2006), e Bins (2007) acompanharam o ensinoaprendizado da linguagem escrita e falada de jovens e adultos com deficiência intelectual. Freitas analisou a escrita de dez jovens e adultos matriculados no ensino fundamental II da EJA. Rubin acompanhou sete jovens e adultos com deficiência intelectual de grau moderado e severo em uma instituição especial 
em relação aos conteúdos de português e matemática e Shimazaki realizou um trabalho de intervenção do ensino-aprendizagem com onze jovens e adultos oriundos de uma instituição especializada. Todas as intervenções foram realizadas no estado do Paraná. De modo geral, as pesquisadoras notaram que a maioria dos participantes escrevia como falava, deixando de lado normas gramaticais e coesivas, além de não serem autônomos nas relações entre os cálculos matemáticos na realização de atividades cotidianas, como compras. Com a intervenção das pesquisadoras houve progressos na leitura e escrita, porém ainda há necessidade da intervenção dos professores em sala de aula no processo ensino-aprendizado, considerando a flexibilização do currículo acadêmico para promover a autonomia acadêmica e cotidiana desses sujeitos.

Sobre a aquisição dos processos de leitura e escrita pelos jovens e adultos com deficiência intelectual, Bins (2007), por meio da análise dos dados pessoais fornecidos pela escola e entrevista semiestruturada com esses alunos, percebeu que muitos passaram por momentos difíceis com familiares, pois estes não acreditavam na alfabetização dos filhos, comprovando o histórico da deficiência intelectual, geralmente marcado pelo fracasso nos momentos de aprendizagem, sendo elas acadêmicas ou cotidianas.

Outra temática encontrada nas pesquisas investigadas refere-se à questão da terminalidade específica. lacono (2004) realizou entrevistas estruturadas com os professores, para analisar em seus discursos quando seus alunos poderiam receber a terminalidade específica. Nesses discursos, destacam-se relatos sobre a baixa autoestima entre os alunos, além da não aprendizagem destes na EJA. Ainda, tais docentes enfatizaram que seus alunos não poderiam receber tal terminalidade por não terem aprendido todos os conteúdos selecionados pelos docentes, previstos no currículo escolar da EJA.

Carvalho (2004) e Tinós (2010) analisaram as trajetórias escolares de jovens e adultos com deficiência intelectual. Carvalho (2004) realizou observação direta do cotidiano escolar de uma instituição, de onde realizou a coleta de dados, bem como observações das dinâmicas realizadas com esses jovens dentro da sala de aula. Os dados obtidos revelaram que grande parte desses jovens eram considerados pelos professores, pelos funcionários da instituição e responsáveis da instituição, como incapazes biologicamente. Já Tinós (2010), por sua vez, analisou os tipos de serviços da escola comum e da instituição, oferecidos e disponíveis nos relatos de seus participantes. Esta investigadora identificou diferentes tipos de serviços, principalmente 
porque as necessidades específicas das participantes eram diferentes. Além disso, um dos fatores analisados nas falas das participantes foi que ambas dependeram de serviços especializados, e um dos sujeitos da pesquisa relatou que a escola especializada é caracterizada por ser um espaço de exclusão. Ambas as autoras concluíram que os direitos e os serviços que deveriam estar disponíveis às pessoas com deficiência são em sua maioria garantidos pelos próprios sujeitos, pelos professores, do que propriamente dito pelas políticas afins.

Travagline (2004) e Xavier (2004) analisaram as possíveis interações entre os jovens e adultos com deficiência intelectual e seus amigos da escola, por isso consideraram as situações de interação em locais como o pátio - na hora do intervalo - a sala de aula, sendo enfatizado o contato entre esses sujeitos, bem como os diálogos ocorridos nesses diferentes espaços. As autoras observaram minuciosamente as interações sociais desses jovens e adultos com deficiência intelectual. Travagline (2004) realizou intervenções com os alunos e notou maior interação entre seus pares. A pesquisadora enfatizou a necessidade de mais envolvimento por parte dos docentes para com o aprendizado desses alunos, bem como de mais consideração pelos docentes sobre o que esses alunos dialogam e o que têm para compartilhar, principalmente dentro de sala de aula. Já Xavier (2004) não utilizou intervenções para não interferir nas relações dos sujeitos nos espaços escolares. Ainda que tais estudos selecionados sinalizassem a necessidade de aprimoramento das práticas pedagógicas, há ainda o que se considerar sobre a importância da interação dos jovens e adultos com deficiência intelectual e seus professores, bem como sobre o entendimento quanto à certificação de escolaridade desses alunos.

No trabalho de Sólera (2008), a autora analisou e investigou as concepções dos funcionários sobre a diferença/deficiência da instituição Pestalozzi de uma cidade localizada na grande São Paulo. Por meio da observação participante, a investigadora percebeu todas as ações e demonstrações que os funcionários tinham relativamente aos alunos com deficiência intelectual da instituição pesquisada. Notou-se que com as reuniões da pesquisadora os funcionários tiveram respeito pelas opiniões dos jovens e adultos, levando em consideração suas vontades conforme sua idade cronológica.

O interesse em conhecer as tendências de pesquisas sobre educação de jovens e adultos com deficiência intelectual possibilitou-nos verificar a existência de poucos estudos sobre a população em questão. Com isso, há a necessidade de refletir sobre a escolarização desse alunado na EJA, e as práticas pedagógicas concernentes devem ser consideradas, além dos conteúdos curriculares a serem utilizados. 
De acordo com Rodrigues (2010, p. 57-58):

[...] a necessidade de se superar o processo pedagógico da educação de jovens e adultos [...] é um desafio para os educadores estabelecer um processo pedagógico que se articule com as determinações estruturais e as experiências subjetivas e coletivas que envolvem a diversidade encontrada na educação de jovens e adultos.

\section{Considerações finais}

Verifica-se a urgência de pesquisas que visem à interface entre a Educação Especial e a Educação de Jovens e Adultos, como resposta ao direito de alunos jovens e adultos com deficiência no acesso e permanência em uma escola de qualidade, bem como a oportunidade de ampliação de escolarização, formação para a inserção no mundo do trabalho e efetiva participação social dessas pessoas.

Considerando que o presente estudo compõe uma das etapas de pesquisa do projeto "Educação Especial na Educação de Jovens e Adultos: relação entre escolarização e trabalho", espera-se que as informações levantadas, pautadas na análise descritiva, crítica e interpretativa possibilitem reflexões sobre as convergências e divergências entre as diferentes realidades da educação de jovens e adultos com deficiência intelectual encontradas nas pesquisas brasileiras, assim como a compreensão sobre a escolarização desse alunado, e uma necessária abertura à futuras pesquisas.

Além disso, é imprescindível a existência de políticas públicas efetivas que contemplem investimentos financeiros, técnicos e científicos à educação de jovens e adultos com deficiência intelectual, normalmente marcados pela exclusão e pela impossibilidade de serem tratados como cidadãos.

\section{Referências}

BINS, K. L. G. Aspecto psico-sócio-culturais envolvidos na alfabetização de jovens e adultos deficientes mentais. 2007. 104 f. Dissertação (Mestrado em Educação). Programa de Pós-graduação em Educação. Pontifícia Universidade Católica do Rio Grande do Sul, Rio Grande do Sul, 2007.

BRASIL. Ministério da Educação. Constituição da República Federativa do Brasil, Brasília, DF. 1988. 
BRASIL. Ministério da Educação. Lei de Diretrizes e Bases da Educação (Lei 9.394/96). Brasília, 1996.

Mistério da Educação. Política Nacional de Educação Especial na perspectiva da educação Inclusiva. Ministério da Educação. Brasília, 2008. Acesso: 20 jul. 2009.15 p.

. Ministério da Educação. CAPES. Banco de Teses. Disponível em: <http://capes.gov.br/servocos/bancoteses.html>. Acesso em: 15 jun. 2009.

. Ministério da Educação. Resolução CNE/CEB n. 2/2001, de 11 set. 2001. Institui diretrizes nacionais para a Educação Especial na Educação Básica. Brasília, DF, 2001. 5 p.

CARVALHO, M. F. A relação com o conhecimento: condições de possibilidades no enfrentamento da deficiência mental. 2004. $197 \mathrm{f}$. Tese (Doutorado em Educação). Faculdade de Educação. Universidade Estadual de Campinas. Campinas, 2004.

GIL, A. C. Como elaborar projetos de pesquisa. 4. ed, São Paulo: Atlas, 2008. 159 p.

DI PIERRO, M. C. Luta social e reconhecimento jurídico do Direito Humano dos jovens e adultos à educação. Revista Educação, Santa Maria, v. 33, n. 3, p. 395-410, set./dez. 2008. Disponível em: <http://www.ufsm.br/ revistaeducacao>. Acesso em: 22 set.2011.

FREITAS, J. F. S. Textualização e ação pedagógica: um estudo com aluno deficiente mental. 2008. 147 f. Dissertação (Mestrado em Educação). Programa de Pós- graduação em Educação Universidade Estadual de Maringá, Maringá, 2008.

GONÇALVES, T. G. G. L.; MELETTI, S. Escolarização de alunos com deficiência da educação de jovens e adultos: uma análise dos indicadores educacionais brasileiros (2007-2010). In: VI SEMINÁRIO NACIONAL DE PESQUISA EM EDUCAÇÃO ESPECIAL, 6, 2011, Nova Almeida. Anais... Nova Almeida: Universidade Federal do Espírito Santo, 2011.p. 1-12.

HADDAD, S; DI PIERRO, M. C. Aprendizagem de Jovens e Adultos - avaliação da década da educação para todos. São Paulo: Perspectiva, v. 14, n. 1, p. 29-40, 2000.

IACONO, J. P. Deficiência mental e terminalidade específica: novas possibilidades de inclusão ou exclusão velada? 2004. 249 f. Dissertação 
(Mestrado em Educação). Programa de Pós- graduação em Educação. Universidade Estadual de Maringá, Maringá, 2004.

LIMA, T. C. S.; MIOTO, R. C. T. Procedimentos metodológicos na construção do conhecimento científico: a pesquisa bibliográfica. Revista Katálysis, Florianopolis, v. 10 n. esp., p. 37-45, fev./abr.2007.

LUCKASSON, R. et al. Mental Retardation - Definition, Classification and Systems of Supports. 10 .ed. Washington (DC): American Association on Mental Retardation, 2002.

MENDES, E. G. A. radicalização do debate sobre inclusão escolar no Brasil. Revista Brasileira de Educação, Rio de Janeiro, v. 11, n. 33, p. 387-559, set./dez. 2006.

MORAES, S. C. A. EJA como espaço de inclusão e empoderamento. In: MORAES, S. C. A. (Org.). Educação Especial na EJA: contemplando a diversidade. Porto Alegre: Prefeitura Municipal de Educação, 2007. p. 13-22.

NUNES, L. R. O. P., GLAT, R., FERREIRA, J. R., MENDES, E. G. Questões atuais em educação especial: pesquisa em educação especial na pósgraduação. v. III. Rio de Janeiro: Sette Letras, 1998. 135 p.

PRIETO, R. G. Atendimento escolar de alunos com necessidades educacionais especiais; um olhar sobre as políticas públicas de educação no Brasil. In: MANTOAN, M. T. E.; PRIETO, R. G.; ARANTES, V. A. (Orgs.). Inclusão Escolar: pontos e contrapontos. 4. ed. São Paulo: Summus, 2006. p. 31-73.

RODRIGUES, R. L. Estado e Políticas para a educação de jovens e adultos: desafios e perspectivas para um projeto de formação humana. In: DALBEN, A. et al. (Org.). Convergência e tensões no campo da formação e do trabalho docente. Belo Horizonte: Autêntica, 2010. p. 44- 59.

RUBIN, M. H. Educação de jovens e adultos com deficiência mental: análise evolutiva da aprendizagem da língua portuguesa e da matemática. 2003. 138 f. Dissertação (Mestrado em Educação Especial) - Programa de Pós-Graduação em Educação Especial. Universidade Federal de São Carlos, São Carlos, 2003.

SHIMAZAKI, E. M. Letramento em jovens e adultos com deficiência mental. 2006. 188 f. Tese (Doutorado em Educação). Faculdade de Educação. Universidade de São Paulo. São Paulo, 2006. 
SMITH, D. Introdução à educação especial: ensinar em tempos de inclusão. 5. ed. Porto Alegre: Artmed, 2008.

SÓLERA, M. C. O. G. É possível à inclusão? Um estudo sobre as dificuldades da relação do sujeito com a diferença. 2008. 118 f. Dissertação (Mestrado em Psicologia). Instituto de Psicologia. Universidade de São Paulo. São Paulo, 2008.

TINÓS, L. M. S. Caminhos de alunos com deficiências à Educação de Jovens e Adultos: conhecendo e compreendendo trajetórias escolares. 2010. 137 f. Tese (Doutorado em Educação Especial). Programa de Pósgraduação em Educação Especial. Universidade Federal de São Carlos, São Carlos, 2010.

TRAVAGLINI, R. R. Análise do processo de alfabetização de Jovens e Adultos com Deficiência Mental. 2004. 89 f. Dissertação (Mestrado em Educação). Programa de Pós-graduação em Educação. Universidade Metodista de Piracicaba. Piracicaba, 2004.

XAVIER, D. R. Possibilidades dialógicas e interações sociais de jovens com deficiência mental no contexto da escola especial. 2007. 75 f. Dissertação (Mestrado em Educação). Faculdade de Ciências Humanas. Universidade Metodista de Piracicaba. Piracicaba, 2007.

\section{Correspondência}

Jéssica de Brito - Universidade Federal de São Carlos, Centro de Educação e

Ciências Humanas, Departamento de Psicologia. Rodovia Washington Luis, KM 235, Monjoalinho, CEP: 13565-905 - São Carlos, São Paulo - Brasil.

E-mail: debrito_jessica@yahoo.com.br - jappcampos@gmail.com

Recebido em 28 de fevereiro de 2012

Aprovado em 04 de julho de 2012 